\title{
Prevalence of Toxoplasma gondii Infection in Healthy Volunteer Blood Donors Using Serological and Molecular Methods from Chaharmahal and Bakhtiari Province, Southwest Iran
}

\author{
Kourosh Manouchehri Naeini (iD ${ }^{1}$, Ehsan Heidari Soureshjani (iD ${ }^{2,3}$, Mahnaz Jafari (i) ${ }^{1}$, Shahrbanou \\ Parchami (iD ${ }^{4}$, Gharib Karimi (iD ${ }^{2}$ and Rahman Abdizadeh (iD) ${ }^{1, *}$ \\ ${ }^{1}$ Department of Medical Parasitology and Mycology, Faculty of Medicine, Shahrekord University of Medical Sciences, Shahrekord, Iran \\ ${ }^{2}$ Blood Transfusion Research Center, High Institute for Research and Education in Transfusion Medicine, Tehran, Iran \\ ${ }^{3}$ Shahrekord Regional Blood Transfusion Center, Shahrekord, Iran \\ ${ }^{4}$ Cellular and Molecular Research Center, Shahrekord University of Medical Sciences, Shahrekord, Iran \\ "Corresponding author: Department of Medical Parasitology and Mycology, Faculty of Medicine, Shahrekord University of Medical Sciences, Shahrekord, Iran. Email: \\ r.abdizadeh57@gmail.com
}

Received 2019 February 26; Revised 2019 May 04; Accepted 2019 May 06.

\begin{abstract}
Background: Toxoplasmosis is a ubiquitous zoonotic disease caused by Toxoplasma gondii. Blood and blood products can be a probable route of $T$. gondii transmission, especially in patients undergoing multiple transfusions.

Objectives: The aim of this cross-sectional study was to determine the prevalence of T. gondii infection among healthy blood donors in Chaharmahal and Bakhtiari province.

Methods: We collected 385 blood samples from blood donors referring to the three biggest Blood Transfusion Organization Centers in the province during the period from January to June 2017. IgG and IgM antibodies against T. gondii were examined using enzymelinked immunosorbent assay. Moreover, all samples were tested by loop-mediated isothermal amplification (LAMP) method for the detection of DNA of T. gondii.

Results: The seroprevalence rates of IgG and IgM anti-T. gondii antibodies were $37.9 \%$ and $1.56 \%$, respectively. With the LAMP method, $1.56 \%$ of the samples were positive for the DNA of T. gondii. Of these, four (1.04\%) were seropositive for both IgG and IgM and two $(0.52 \%)$ were positive only for IgG. Moreover, statistical analyses indicated that several risk factors including gender, age, contact with cats, and consumption of undercooked meat were significantly related to T. gondii seropositivity in blood donors.

Conclusions: This study indicated that anti-T. gondii antibodies were highly prevalent among apparently healthy blood donors in Southwest Iran. There was a possibility of infection transmission by blood transfusion while there is a lack of screening tests for Toxoplasma infection in the Blood Transfusion Organizations. It is strongly suggested that appropriate and sensitive screening programs be designed by the LAMP method for the detection of $T$. gondii in blood donors.
\end{abstract}

Keywords: Blood Donors, Toxoplasmosis, Seroprevalence, Loop-Mediated Isothermal Amplification, Chaharmahal and Bakhtiari Province

\section{Background}

Toxoplasmosis is one of the widespread serious zoonotic parasitic diseases in humans and animals worldwide caused by a single-cell obligate intracellular opportunistic protozoan belonging to the phylum Apicomplexa (1). Human toxoplasmosis occurs postnatally (horizontally) through consuming or handling viable tissue cysts of undercooked or raw meat, consuming contaminated food (unwashed raw fruits and vegetables), and drinking water contaminated with sporulated oocysts or unpasteurized milk containing viable tachyzoites. Moreover, tachyzoites in the blood may be crossed to the fetus via the placenta when an uninfected woman acquires the infection during pregnancy $(2,3)$. Another way of infection transmission is through organ transplantation or blood transfusion from infected donors to susceptible recipients (Toxoplasma-seronegative patients) (4-8).

Epidemiological surveys demonstrate that toxoplasmosis has a global distribution with a highly variable prevalence from $1 \%$ to $90 \%$ in various areas of different countries. It is estimated that approximately $25 \%$ to $30 \%$ of the world's population is chronically infected with Toxoplasma gondii, especially in developing countries $(4,9)$. Human toxoplasmosis in healthy adults with normal im- 
mune systems is usually an asymptomatic chronic disease without clinical symptoms or with self-limited symptoms. However, in the fetus and newborns who are congenitally infected, it can cause congenital anomalies such as stillbirth, microcephaly, hydrocephalus, mental retardation, abortion, cerebral calcification in the developing fetus, and fetal death (10). Moreover, in immunosuppressed patients, such as AIDS patients, patients undergoing therapies for malignancies, recipients of solid-organ transplants, and people on hemodialysis, it causes irreversible complications including encephalitis, pneumonia, and disseminated systematic disease $(11,12)$.

Another risk group consists of patients with aplastic anemia, sickle cell anemia, thalassemia, and lymphoproliferative disorders who receive blood transfusion regularly or frequently for survival. The transfusion of infected blood in these patients due to their immunodeficiency disorders would cause serious disease $(13,14)$. Toxoplasma gondii is one of the intracellular microorganisms that can stay alive for up to 50 days in the citrated blood and the buffy coat at $5^{\circ} \mathrm{C}(15)$. Therefore, this parasite is potent for transmission via blood and blood components such as leukocytes. However, many countries do not perform rigorous screening on blood as a routine procedure before blood transfusion. Therefore, scientific surveys have been carried out to investigate the relationship between T. gondii and blood safety in blood donors and blood bags by different techniques such as serological and molecular methods. Many investigations have indicated that the seroprevalence of toxoplasmosis varies widely from $0.96 \%$ to $73.26 \%$ in healthy volunteer blood donors in different countries. In Iran, the seroprevalence of toxoplasmosis in healthy volunteer blood donors is reported from $16.8 \%$ to $56.3 \%$ in different geographic areas $(6,8,16-19)$.

\section{Objectives}

The aim of this cross-sectional study was to evaluate the prevalence of $T$. gondii infection using serological and molecular methods and determine the associated risk factors among healthy blood donors in Chaharmahal and Bakhtiari province, Southwest Iran.

\section{Methods}

\subsection{Study Design}

This cross-sectional study was carried out at the three biggest Blood Transfusion Organization centers of Chaharmahal and Bakhtiari province, Iran. The province is located between $31^{\circ} 09^{\prime}$ North latitude and $32^{\circ} 48^{\prime}$ East longitude in the mountainous areas of Southwestern Iran, covering an area of 16,332 square kilometers, with a population of about 895,263 . It is characterized by various climates from cold, snowy, and rainy weather especially in fall and winter to hot weather in summer. Animal husbandry, farming, and gardening are common in this province and the diet of most people contains meat, milk, and local vegetables.

\subsection{Sample Collection and Participants}

In this study, according to statistical calculations, the sample size was determined to be 385 cases based on the prevalence of $50 \%$ as reported in some studies from Iran $(17,20,21)$, the confidence level of $95 \%$, and the error of 0.05 . Blood samples were collected from apparently healthy blood donors from seven counties of the province, Shahrekord, Lordegan, Boroujen, Farsan, Kiar, Ardal, and Kohrang. The donors referred to the three biggest Blood Transfusion Organization centers in the province during the period from January to June 2017.

Before collecting the blood samples, a questionnaire was administered to inquire about socio-demographic information of the donors including age, sex, job, residence, education level, and blood group. Moreover, other possible risk factors were recorded such as contact with animals (cats), raw/half-cocked meat consumption, raw milk/egg consumption, raw vegetable consumption, and history of blood transfusion. Then, $5 \mathrm{~mL}$ of venous blood was aseptically taken from each apparently healthy donor and divided into two parts. One part was transferred into plastic tubes containing K2EDTA as an anticoagulant for isolating buffy coat for molecular assay and the other part was poured into a disposable tube free of anti-coagulants to isolate sera for serological assay.

The specimen was left for 15 - 30 minutes or put in the water bath at $37^{\circ} \mathrm{C}$. Then, it was centrifuged at $3000 \mathrm{rpm}$ for 5 minutes to separate clear serum. Moreover, all donated blood samples were assayed to determine blood groups and Rh factors. All the blood samples were routinely tested in terms of antibodies against human immunodeficiency virus (HIV), hepatitis C virus (HCV), hepatitis B virus surface antigen (HBsAg), and Treponema pallidum infection. None of the blood donors was seropositive for the infection with these microorganisms. After being collected, the samples were transported to the Parasitology Laboratory, Department of Parasitology and Mycology, Shahrekord University of Medical Sciences, and kept at $-20^{\circ} \mathrm{C}$ until the day of the experiment.

\subsection{Serological Assay}

IgM and IgG antibodies against T. gondii were tested in all serum samples using the commercially available enzyme-linked immunosorbent assay (ELISA) kit (Pishtaz Teb Co. Tehran, Iran) according to the instructions of the manufacturer. The IgG antibody titer was considered positive if the values were $\geq 10 \mathrm{~mL} / \mathrm{IU}$ and negative if they were $<10 \mathrm{~mL} / \mathrm{IU}$. In addition, anti-T. gondii IgM antibody levels of 
$\geq 1.1 \mathrm{~mL} / \mathrm{IU}$ and $<0.9 \mathrm{~mL} / \mathrm{IU}$ were defined as positive and negative, respectively.

\subsection{Molecular Diagnosis}

Loop-mediated isothermal amplification (LAMP) is one of the new easy-to-perform molecular methods for detection of DNA of different microorganisms by nucleic acid amplification with extremely high sensitivity and specificity to discriminate single nucleotides. The technique was performed by a DNA polymerase with strand displacement activity, a set of two specially designed inner primers (FIP and BIP), and two outer primers (F3 and B3) that amplified DNA with high specificity, efficiency, and rapidity under isothermal conditions (22). Therefore, we used LAMP to detect DNA of T. gondii in blood samples of donors.

First, DNA was extracted from buffy coat of all samples by a commercial DNA extraction kit DNG-Plus ${ }^{\mathrm{TM}}$ (DN8118C, Cinnaclon Co., Iran) according to the manufacturer's instructions. Genomic DNA was extracted from the T. gondii tachyzoites of RH strain provided by the Toxoplasmosis Research Center, Mazandaran University of Medical Sciences (Sari, Iran), as a positive control. Then, the concentration and quality of DNA were determined using an ND-1000 spectrophotometer (Nanodrop Technologies, USA). Each $T$. gondii one 80-Mbp genome was equal to about $80 \mathrm{fg}$ DNA. In the LAMP assay, the designed primers were used for 529 bp repeated elements of $T$. gondii (23).

The LAMP assay was carried out in a reaction mixture (25 $\mu \mathrm{L}$ ) containing $1 \mu \mathrm{L}$ of template DNA, 40 pmol of each of FIP and BIP primers, 20 pmol of each of LF and LB primers, 5 pmol of each of F3 and B3 primers, 8 U of Bst DNA polymerase (New England Biolabs, USA), $1.4 \mathrm{mM}$ of deoxynucleoside triphosphates (dNTP), and $2 \times$ reaction buffer $(1.6$ $\mathrm{M}$ betaine (Sigma-Aldrich), $40 \mathrm{mM}$ of Tris- $\mathrm{HCl}$ ( $\mathrm{pH} 8.8$ ), 20 $\mathrm{mM}$ of $\mathrm{KCl}, 20 \mathrm{mM}$ of $\left(\mathrm{NH}_{4}\right)_{2} \mathrm{SO}_{4}, 16 \mathrm{mM}$ of $\mathrm{MgSO}_{4}$, and $0.2 \%$ Tween 20). In order to determine the optimal time and temperature conditions for the LAMP assay, the reactions including positive control (T. gondii RH-strain DNA) and negative control (double distilled water) were carried out at 60 to $67^{\circ} \mathrm{C}$ for $30,45,60$, and 75 minutes (24). Loopmediated isothermal amplification products were visualized by $1.5 \%$ agarose gel electrophoresis stained with ethidium bromide solution $(1 \mu \mathrm{g} / \mathrm{mL})$. In addition, LAMP amplicons in the reaction tube were evaluated by visual inspection that was performed by adding $1 \mu \mathrm{L}$ of 1:10 dilution of SYBR green I (invitrogen lot: 49743A, USA). After the reaction, fluorescent signals of the solutions were observed under UV light.

\subsection{Statistical Analyses}

SPSS 20.0 software (SPSS Inc., Chicago, IL, USA) was used for all descriptive and inferential statistics. The chi-square test was applied to access the univariate association between independent variables and outcome. The association between T. gondii seropositivity and the potential risk factors were evaluated using multifactorial logistic regression model. In this survey, $\mathrm{P}<0.05$ was considered statistically significant.

\section{Results}

\subsection{Participants}

Blood samples in this survey belonged to 385 healthy blood donors, including 365 (94.8\%) men and 20 (5.2\%) women. The participants' mean age \pm SD was $37.2 \pm 9.81$ years, with the youngest and oldest being 20 and 71 years, respectively. Most participants were aged 26 - 35 years, living in urban areas, and had a college education or above.

\subsection{Seroprevalence of Anti-Toxoplasma gondii Antibodies}

The serological tests indicated that anti-T. gondii antibodies were detected in 154 (40\%) serum samples of the 385 blood donors. Moreover, 146 (37.9\%) cases were seropositive for IgG antibody, six (1.56\%) for both IgM and IgG, and four (1.03\%) for IgM antibody alone. Therefore, the prevalence rate of IgG and IgM antibodies against T. gondii was $37.9 \%$ and $1.03 \%$, respectively. Regarding geographical location, as shown by the ELISA test, the seroprevalence rates of anti-T. gondii IgG antibody were 71.2\%, 5.5\%, 5.5\%, 4.8\%, 4.1\%, 4.1\%, $2.3 \%, 2.3 \%$, and 0.7\% in Shahrekord, Saman, Kiar, Farsan, Ardal, Ben, Lordegan, and Koohrang, respectively. In terms of gender, the seroprevalence rate of anti-T. gondii IgG antibody was significantly higher in female donors than in male donors. The rates of anti-T. gondii IgG antibody in females and males were $65 \%$ and $36.4 \%$, respectively.

\subsection{Risk Factors of Anti-Toxoplasma gondii Antibodies}

Several risk factors, including gender, age, residence place, education level, blood type, diet, and contact with cats, which were possibly associated with toxoplasmosis, were evaluated by statistical methods including descriptive and inferential statistics. The results demonstrated that four variables, including gender, age, contact with cats, and consumption of undercooked meat, were significantly related to $T$. gondii seropositivity in blood donors. However, other risk factors and demographic features of blood donors did not show any statistical association with the acquisition of toxoplasmosis (Tables 1 and 2).

\subsection{Detection of Toxoplasma gondii DNA by LAMP}

All blood samples were tested using the LAMP assay for the presence of $T$. gondii DNA. The DNA was found in six (1.56\%) samples, four of which had IgG and IgM anti-T. gondii antibodies and two had only IgG antibody in the serological assay (Figures 1 and 2). 


\begin{tabular}{|c|c|c|c|c|}
\hline \multirow[t]{2}{*}{ Variable } & \multirow[t]{2}{*}{ No. (\%) } & \multicolumn{2}{|c|}{ Seropositive Antibodies } & \multirow[t]{2}{*}{ LAMP Positivity } \\
\hline & & Positive (\%) & Positive IgM (\%) & \\
\hline \multicolumn{5}{|l|}{ Gender } \\
\hline Male & $365(94.8)$ & $133(36.4)$ & $3(0.82)$ & $5(1.37)$ \\
\hline Female & $20(5.2)$ & $13(65)$ & $1(5)$ & $1(5)$ \\
\hline \multicolumn{5}{|l|}{ Age group, y } \\
\hline$<25$ & $42(10.9)$ & $10(23.8)$ & & \\
\hline $26-35$ & $146(37.9)$ & $43(29.6)$ & $3(2.1)$ & $3(2.1)$ \\
\hline $36-45$ & $118(30.6)$ & $55(46.6)$ & $1(0.85)$ & $2(1.7)$ \\
\hline$>45$ & $79(20.5)$ & $38(48.1)$ & & $1(1.27)$ \\
\hline \multicolumn{5}{|l|}{ Residence place } \\
\hline Urban areas & $329(85.5)$ & $127(38.6)$ & $4(1.2)$ & $6(1.8)$ \\
\hline Rural areas & $56(14.5)$ & $19(33.9)$ & & \\
\hline \multicolumn{5}{|l|}{ Education } \\
\hline Illiterate & $4(1)$ & $3(75)$ & & \\
\hline Primary school & $35(9.1)$ & $14(40)$ & & $1(2.86)$ \\
\hline Middle school & $66(17.1)$ & $29(43.9)$ & $1(1.5)$ & $2(3)$ \\
\hline High school & $147(38.2)$ & $51(34.7)$ & $1(0.68)$ & $1(0.7)$ \\
\hline Graduate & $133(34.5)$ & $49(36.8)$ & $2(1.5)$ & $2(1.5)$ \\
\hline \multicolumn{5}{|l|}{ Blood type } \\
\hline $\mathrm{A}^{+}$ & $115(29.9)$ & $39(33.9)$ & $2(1.74)$ & $3(2.6)$ \\
\hline $\mathrm{A}^{-}$ & $15(3.9)$ & $6(40)$ & & $1(6.7)$ \\
\hline $\mathrm{B}^{+}$ & $66(17.1)$ & $35(53)$ & & \\
\hline $\mathrm{B}^{-}$ & $6(1.6)$ & $3(50)$ & $1(50)$ & $1(16.7)$ \\
\hline $\mathrm{AB}^{+}$ & $24(6.2)$ & $10(41.7)$ & & \\
\hline $\mathrm{AB}^{-}$ & $7(1.8)$ & $3(42.9)$ & & \\
\hline $\mathrm{O}^{+}$ & $53(13.8)$ & $13(24.5)$ & & \\
\hline $\mathrm{O}^{-}$ & $99(25.7)$ & $37(37.4)$ & $1(1.01)$ & $1(1.01)$ \\
\hline \multicolumn{5}{|l|}{ Contact with cats } \\
\hline Yes & $49(12.7)$ & $28(57.1)$ & & $1(2)$ \\
\hline No & $336(87.3)$ & $118(35.1)$ & $4(1.2)$ & $5(1.5)$ \\
\hline \multicolumn{5}{|c|}{ Raw/half-cooked meat consumption } \\
\hline Yes & $25(6.5)$ & $11(44)$ & & $1(4)$ \\
\hline No & $360(93.5)$ & $135(37.5)$ & $4(1.1)$ & $5(1.4)$ \\
\hline \multicolumn{5}{|c|}{ Raw milk/egg consumption } \\
\hline Yes & $223(57.9)$ & $85(38.1)$ & $1(0.45)$ & $2(0.9)$ \\
\hline No & $162(42.1)$ & $61(37.7)$ & $3(1.9)$ & $4(2.5)$ \\
\hline \multicolumn{5}{|c|}{ Unwashed vegetables consumption } \\
\hline Yes & $14(3.6)$ & $4(28)$ & $1(7.1)$ & $3(21.4)$ \\
\hline No & $371(94.4)$ & $90(24.3)$ & $3(0.8)$ & $3(0.8)$ \\
\hline \multicolumn{5}{|l|}{ Blood transfusion } \\
\hline Yes & $0(0)$ & & & \\
\hline No & $385(100)$ & $146(37.9)$ & $4(1.03)$ & $6(1.6)$ \\
\hline
\end{tabular}

${ }^{\mathrm{a}}$ Values are expressed as No. (\%).

\section{Discussion}

Organ transplantation and blood transfusion can be of the potential transmission routes of $T$. gondii. These routes of transmission are less common; however, if donors are infected, it will cause acute toxoplasmosis because the recipients are usually immunocompromised patients, with significant clinical consequences such as encephalitis, brain abscess, myocarditis, and chorioretinitis (10). Despite the serious complications of this parasitic disease, es- 


\begin{tabular}{|c|c|c|c|c|c|}
\hline Variable & No. (\%) & Seropositive Antibodies IgG (\%) & PValue & OR & 95\% CI \\
\hline \multicolumn{6}{|l|}{ Gender } \\
\hline Male & $365(94.8)$ & $133(36.4)$ & $0.015^{\mathrm{b}}$ & 3.240 & $1.261-8.320$ \\
\hline Female & $20(5.2)$ & $13(65)$ & - & 1 & \\
\hline \multicolumn{6}{|l|}{ Age group, y } \\
\hline$<25$ & $42(10.9)$ & $10(23.8)$ & 0.011 & 2.966 & $1.285-6.843$ \\
\hline $26-35$ & $146(37.9)$ & $43(29.6)$ & $0.006^{\mathrm{b}}$ & 2.220 & $1.259-3.914$ \\
\hline $36-45$ & $118(30.6)$ & $55(46.6)$ & 0.837 & 1.062 & $0.60-1.878$ \\
\hline$>45$ & $79(20.5)$ & $38(48.1)$ & - & 1 & \\
\hline \multicolumn{6}{|l|}{ Residence place } \\
\hline Urban areas & $329(85.5)$ & $127(38.6)$ & 0.506 & 0.817 & $0.450-1.482$ \\
\hline Rural areas & $56(14.5)$ & $19(33.9)$ & - & 1 & \\
\hline \multicolumn{6}{|l|}{ Education } \\
\hline Illiterate & $4(1)$ & $3(75)$ & 0.161 & .194 & $0.020-1.921$ \\
\hline Primary school school & $35(9.1)$ & $14(40)$ & 0.731 & 0.875 & $0.408-1.876$ \\
\hline Middle school school school & $66(17.1)$ & $29(43.9)$ & 0.335 & 0.744 & $0.408-1.357$ \\
\hline High school & $147(38.2)$ & $51(34.7)$ & 0.708 & 1.098 & $0.673-1.791$ \\
\hline Graduate & $133(34.5)$ & $49(36.8)$ & - & 1 & \\
\hline \multicolumn{6}{|l|}{ Blood type } \\
\hline $\mathrm{A}^{+}$ & $115(29.9)$ & $39(33.9)$ & 0.598 & 1.163 & $0.664-2.038$ \\
\hline $\mathrm{A}^{-}$ & $15(3.9)$ & $6(40)$ & 0.845 & 0.895 & $0.295-2.717$ \\
\hline $\mathrm{B}^{+}$ & $66(17.1)$ & $35(53)$ & 0.048 & 0.529 & $0.281-0.994$ \\
\hline $\mathrm{B}^{-}$ & $6(1.6)$ & $3(50)$ & 0.540 & 0.597 & $0.114-3.111$ \\
\hline $\mathrm{AB}^{+}$ & $24(6.2)$ & $10(41.7)$ & 0.698 & 0.835 & $0.337-2.071$ \\
\hline $\mathrm{AB}^{-}$ & $7(1.8)$ & $3(42.9)$ & 0.773 & 0.796 & $0.169-3.754$ \\
\hline $\mathrm{O}^{+}$ & $53(13.8)$ & $13(24.5)$ & 0.111 & 1.836 & $0.870-3.874$ \\
\hline $\mathrm{O}^{-}$ & $99(25.7)$ & $37(37.4)$ & - & 1 & \\
\hline \multicolumn{6}{|l|}{ Contact with cats } \\
\hline Yes & $49(12.7)$ & $28(57.1)$ & $0.004^{\mathrm{b}}$ & 0.406 & $0.221-0.746$ \\
\hline No & $336(87.3)$ & $118(35.1)$ & - & 1 & \\
\hline \multicolumn{6}{|l|}{ Raw/half-cooked meat consumption } \\
\hline Yes & $25(6.5)$ & $11(44)$ & $0.004^{\mathrm{b}}$ & 0.406 & $0.221-0.746$ \\
\hline No & $360(93.5)$ & $135(37.5)$ & - & 1 & \\
\hline \multicolumn{6}{|l|}{ Raw milk/egg consumption } \\
\hline Yes & $223(57.9)$ & $85(38.1)$ & 0.926 & 0.981 & $0.646-1.488$ \\
\hline No & $162(42.1)$ & $61(37.7)$ & - & 1 & \\
\hline \multicolumn{6}{|l|}{ Unwashed vegetables consumption } \\
\hline Yes & $14(3.6)$ & $4(28)$ & 0.826 & 1.049 & $0.686-1.603$ \\
\hline No & $371(94.4)$ & $90(24.3)$ & - & 1 & \\
\hline \multicolumn{6}{|l|}{ Blood transfusion } \\
\hline Yes & $0(0)$ & & & & \\
\hline No & $385(100)$ & $146(37.9)$ & & & \\
\hline
\end{tabular}

Abbreviation: OR: odds ratio.

${ }^{\mathrm{a}}$ Values are expressed as No. (\%).

${ }^{\mathrm{b}} \mathrm{P}<0.05$, statistically significant difference.

pecially in immunocompromised patients, available treatments are not fully effective; moreover, safe and efficacious vaccines are not available; thus, the prevention of parasite transmission is one of the effective strategies for re- ducing toxoplasmosis (25). Detecting the source of infection such as infected blood and organs for recipient candidates, especially patients undergoing multiple transfusions or those requiring blood transfusion for transplan- 


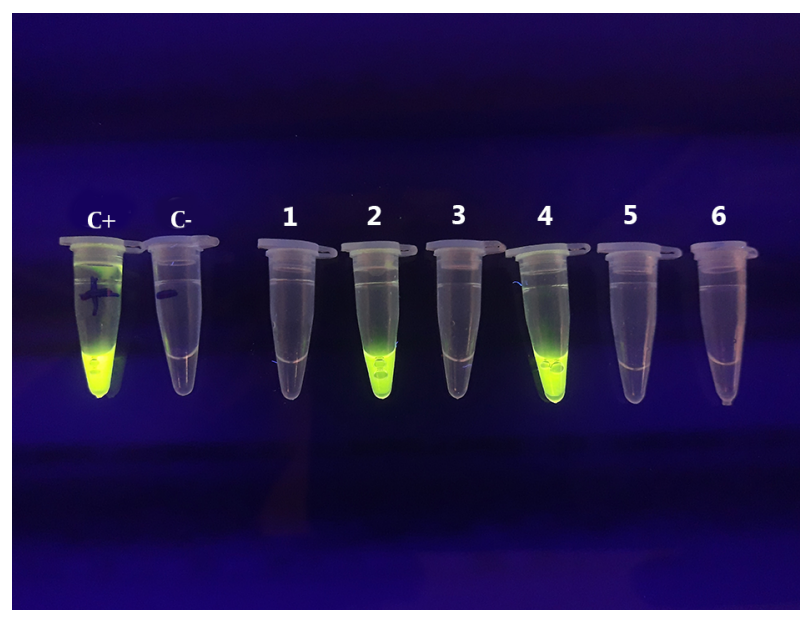

Figure 1. Amplification of Toxoplasma gondii DNA in blood samples using the LAMP assay; positive reactions turned green after the addition of SYBR green I while the negative reactions remained uncolored; $\mathrm{C}+$, positive control; $\mathrm{C}-$, negative control; tubes $1-6$, randomly selected samples from patients.

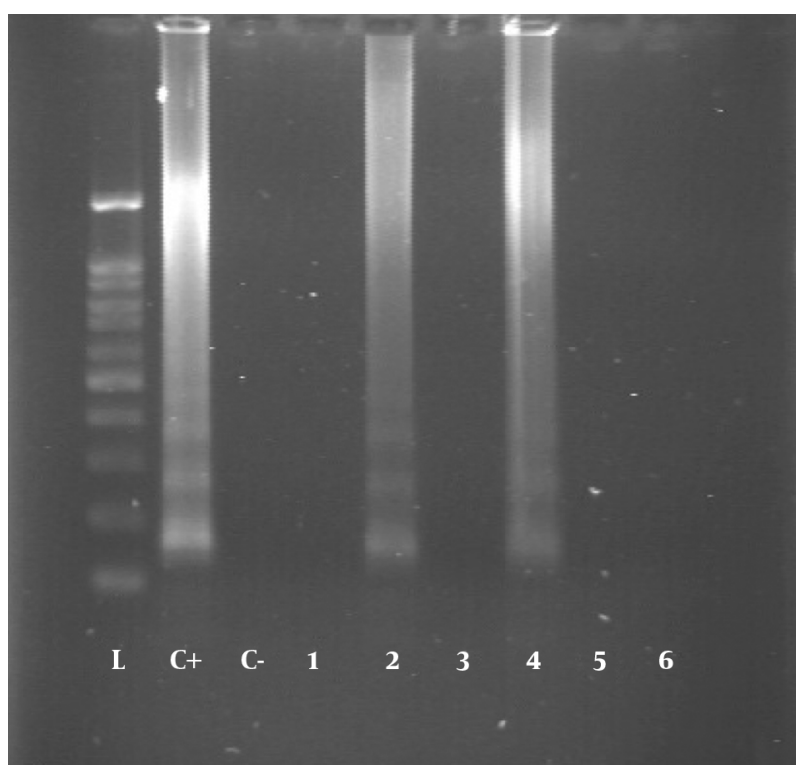

Figure 2. Amplification of T. gondii DNA in blood samples using the LAMP assay on $1.5 \%$ agarose gel staining with ethidium bromide. L, $100 \mathrm{bp}$ molecular weight marker; C+, positive control; C-, negative control; lanes 1-6, randomly selected samples from patients.

tation management, can be crucial to control and prevent toxoplasmosis (16). Currently, T. gondii screening in blood and blood products of blood donors is not routinely considered in worldwide therefore certainly do not assay the relationship between $T$. gondii and blood safety in blood transfusion centers.

In this study, 385 blood samples were collected from healthy blood donors from Chaharmahal and Bakhtiari province, Iran, and were evaluated by serological and molecular methods for $T$. gondii infection. The results indicated that 154 (40\%) samples were seropositive for anti-T. gondii antibodies while $37.9 \%$ and $1.56 \%$ were positive for IgG and IgM anti-T. gondii antibodies, respectively. These findings showed a considerable prevalence rate of toxoplasmosis in this population. Although seropositivity of IgG (latent infection) was high, the rate of anti-T. gondii IgM antibodies (acute infection) was low.

Previous investigations conducted in Iran showed that the seroprevalence of $T$. gondii in volunteer blood donors was reported to be $34.4 \%$ (95\% CI: $24.9 \%$ - 43.9\%), ranging from $18.3 \%$ in Gonabad city (26) to $56.4 \%$ in Hamedan province (20). However, different rates were reported for various regions by serological methods for IgG and IgM antibodies respectively as $25 \%$ and $0 \%$ in Zahedan (Southeast Iran) (27), 25\% and 3.2\% in Mashhad (Northeast Iran) (28), $37.8 \%$ and $0 \%$ in Urmia (Northwest Iran) (29), 38.66\% and $1.03 \%$ in Tabriz (Northwest Iran) (21), 16.30\% and $0.7 \%$ in Boyer-Ahmad county (Southwest Iran), 34.47\% and 0.5\% in Ahvaz (Southwest Iran) (17), and 28.8\% and 3.2\%in Kerman (Southeast Iran) (30), which may be related to living conditions, geographical and environmental factors, sanitary conditions, economic and social situation of blood donors, sample size, and sensitivity of detection methods.

The overall seroepidemiological studies of T. gondii on blood donors in different regions of the world indicated very different prevalence rates for IgG and IgM antibodies from $0.64 \%$ and $0 \%$ to $70.29 \%$ and $5.81 \%$, respectively (8). The highest seroprevalence rates were from Brazil (75\%)(31) and Ethiopia (73\%) (32) while low seroprevalence rates of toxoplasmosis in blood donors were observed in Namibia (0.96\%) (33), Thailand (9.6\%), Taiwan (9.3\%), and Mexico (7.4\%) (17).

In the present study, the obtained results showed that the seroprevalence of $T$. gondii was significantly higher in female than in male donors, which may be due to sampling bias because most blood donors were males. Similarly, Mahmoudvand et al. (30) and Sundar et al. (34) reported that the seroprevalence of $T$. gondii in female donors was significantly higher than that in male donors. However, some studies reported contradictory results $(28,35)$.

According to a recently published systematic review of toxoplasmosis in Iranian blood donors, the difference between men and women was not statistically significant (36). Regarding age groups, IgG positivity was more frequent in donors aged $>45$ years that was similar to other studies indicating that the rate of seropositivity increased with age as a consequence of the increased opportunity of acquiring the infection. The obtained findings disclosed that blood donors with blood group B+ had more Toxoplasma seropositivity than other blood groups; however, 
no correlation was found between $T$. gondii seropositivity and blood groups. Shaapan et al. reported that blood group A (48.7\%) had the most frequent Toxoplasma seropositivity among blood donors from Egypt (37). However, Mahmoudvand et al., (30) Shaddel et al., (38) and Elsheikha et al. (19) indicated a significant correlation between toxoplasmosis and blood groups $\mathrm{AB}, \mathrm{A}$, and $\mathrm{O}$, respectively. Due to the small number of reports of the correlation between toxoplasmosis and blood groups, this hypothesis needs to be confirmed in further investigations.

Although cats are the definitive host of this protozoon and infected cats can infect the environment by defecated oocysts, conflicting findings have been reported concerning the transmission of $T$. gondii via contact with cats. However, our study suggested that contact with cats is a potential risk factor for acquiring toxoplasmosis. Concerning food habits, the study exhibited that the seroprevalence rate of toxoplasmosis was higher in blood donors who consumed raw/half-cooked meat than in other blood donors. Therefore, ingesting meat containing tissue cysts seems to be the main route of infection among the other routes. Moreover, some studies such as Mahmoudvand et al. study confirmed this finding (30). In this study, no significant relationships were found between the consumption of raw vegetables, occupational activities, education level, residence place, blood transfusion, and raw milk/egg consumption (as potential risk factors for acquiring toxoplasmosis) and seropositivity of T. gondii.

Despite this fact that serological methods such as ELISA are used in many medical diagnostic laboratories for detecting antibodies against $T$. gondii, these methods have false-positive results and cannot differentiate past and present infections; therefore, the diagnosis of toxoplasmosis remains unsatisfactory with serological methods. This is while molecular methods can obviate this limitation (39, 40). Many researchers have used molecular methods such as PCR and real-time PCR for detecting T. gondii in blood donors. Studies carried out based on the detection of DNA of T. gondii in blood donors in Iran indicated that $0.9 \%$ of IgM-positive samples in Kerman (30), 6.97\% samples in Rafsanjan (18), 40\% of seropositive samples in Ahvaz (17), and $100 \%$ of IgM-positive samples in Razavi Khorasan (41) contained the DNA of the parasite. Nevertheless, by the PCR method, $T$. gondii DNA was not detected in the buffy coat of any of the seropositive cases in Boyer-Ahmad County, Southwest Iran (42).

Our findings according to the molecular assay demonstrated that six (1.56\%) samples had the DNA of T. gondii. Of these, four (1.04\%) were seropositive for both IgG and IgM antibodies and two (0.52\%) were positive only for IgG antibody. In line with these findings, Fallahi et al. reported that LAMP is a useful tool for the diagnosis of toxoplasmosis in children with leukemia with high sensitivity and specificity (24). Loop-mediated isothermal amplification is an attractive DNA amplification method compared to other molecular methods such as PCR because it requires a minimal DNA sample such as a single tachyzoite or 10 copies of recombinant plasmid whereas the PCR method in toxoplasmosis diagnosis needs much more DNA sample $(24,39)$. Furthermore, the LAMP assay was very simple, as the reaction would be carried out in a single tube under one isothermal condition and at one-hour reaction time. Therefore, the LAMP method has the advantages of specificity, rapidity, sensitivity, and easiness for the clinical diagnosis of $T$. gondii (43).

\subsection{Conclusions}

In conclusion, the results demonstrated that the prevalence of $T$. gondii infection is high among apparently healthy blood donors in Southwest Iran. Thus, there is the possibility of transmission of infection by blood transfusion while screening tests are not used to detect Toxoplasma infection in Blood Transfusion Organizations. Furthermore, serological methods have potential weaknesses such as time-intensiveness and false-positive results. Therefore, it is strongly suggested that appropriate and sensitivity programs be designed for screening of toxoplasmosis by the LAMP method to detect T. gondii DNA in blood donors and prevent the transmission of T. gondii to at-risk people, especially multi-transfused patients.

\section{Acknowledgments}

The authors would like to thank the staff of Shahrekord Blood Transfusion Organization for sample collection and the Cellular and Molecular Research Center, Shahrekord University of Medical Sciences.

\section{Footnotes}

Authors' Contribution: Rahman Abdizade, Kourosh Manouchehri Naeini, and Gharib Karimi conceived and designed the study. Ehsan Heidari Soureshjani helped to samples collected. Mahnaz Jafari and Shahrbanou Parchami performed laboratory works. Rahman Abdizade and Kourosh Manouchehri Naeini drafted the paper and revised the manuscript for important intellectual content.

Conflict of Interests: It is not declared by the authors.

Ethical Approval: This survey was approved by the Ethics Committee of Shahrekord University of Medical Sciences (IR.SKUMS.REC.1394.238).

Financial Disclosure: It is not declared by the authors.

Funding/Support: The study was supported financially by the grant (No. 1394-01-70-2514) provided by the Faculty 
of Medicine, Shahrekord University of Medical Sciences, Shahrekord, Iran.

Patient Consent: Written informed consent was obtained from all participants before blood sampling.

\section{References}

1. Rahimi MT, Daryani A, Sarvi S, Shokri A, Ahmadpour E, Teshnizi SH, et al. Cats and Toxoplasma gondii: A systematic review and meta-analysis in Iran. Onderstepoort J Vet Res. 2015;82(1):e1-e10. doi: 10.4102/ojvr.v82i1.823. [PubMed: 26017063]. [PubMed Central: PMC6238687].

2. Dubey JP. Toxoplasmosis-a waterborne zoonosis. Vet Parasitol. 2004;126(1-2):57-72. doi: 10.1016/j.vetpar.2004.09.005. [PubMed: 15567579].

3. Belluco S, Mancin M, Conficoni D, Simonato G, Pietrobelli M, Ricci A. Investigating the determinants of Toxoplasma gondii prevalence in meat: A systematic review and meta-regression. PLoS One. 2016;11(4). e0153856. doi: 10.1371/journal.pone.0153856. [PubMed: 27082633]. [PubMed Central: PMC4833317].

4. Tenter AM, Heckeroth AR, Weiss LM. Toxoplasma gondii: From animals to humans. Int J Parasitol. 2000;30(12-13):1217-58. doi: 10.1016/S00207519(00)00124-7. [PubMed: 11113252]. [PubMed Central: PMC3109627].

5. Dubey JP, Jones JL. Toxoplasma gondii infection in humans and animals in the United States. Int J Parasitol. 2008;38(11):1257-78. doi: 10.1016/j.ijpara.2008.03.007. [PubMed:18508057].

6. Sarkari B, Shafiei R, Zare M, Sohrabpour S, Kasraian L. Seroprevalence and molecular diagnosis of Toxoplasma gondii infection among blood donors in southern Iran. J Infect Dev Ctries. 2014;8(4):543-7. doi: 10.3855/jidc.3831. [PubMed: 24727522]

7. Slavin MA, Meyers JD, Remington JS, Hackman RC. Toxoplasma gondii infection in marrow transplant recipients: A 20 year experience. Bone Marrow Transplant. 1994;13(5):549-57. [PubMed: 8054907].

8. Foroutan-Rad M, Majidiani H, Dalvand S, Daryani A, Kooti W, Saki J, et al. Toxoplasmosis in blood donors: A systematic review and meta-analysis. Transfus Med Rev. 2016;30(3):116-22. doi: 10.1016/j.tmrv.2016.03.002. [PubMed: 27145927].

9. Daryani A, Sarvi S, Aarabi M, Mizani A, Ahmadpour E, Shokri A, et al. Seroprevalence of Toxoplasma gondii in the Iranian general population: A systematic review and meta-analysis. Acta Trop. 2014;137:18594. doi: 10.1016/j.actatropica.2014.05.015. [PubMed: 24887263]

10. Bhopale GM. Pathogenesis of toxoplasmosis. Comp Immunol Microbiol Infect Dis. 2003;26(4):213-22. doi: 10.1016/S0147-9571(02)00058-9. [PubMed: 12676122].

11. Machala L, Kodym P, Maly M, Geleneky M, Beran O, Jilich D. [Toxoplasmosis in immunocompromised patients]. Epidemiol Mikrobiol Imunol. 2015;64(2):59-65. Czech. [PubMed: 26099608].

12. Wang ZD, Liu HH, Ma ZX, Ma HY, Li ZY, Yang ZB, et al. Toxoplasma gondii infection in immunocompromised patients: A systematic review and meta-analysis. Front Microbiol. 2017;8:389. doi: 10.3389/fmicb.2017.00389. [PubMed: 28337191]. [PubMed Central: PMC5343064].

13. Mele A, Paterson PJ, Prentice HG, Leoni P, Kibbler CC. Toxoplasmosis in bone marrow transplantation: A report of two cases and systematic review of the literature. Bone Marrow Transplant. 2002;29(8):6918. doi: 10.1038/sj.bmt.1703425. [PubMed:12180115].

14. Wendel Neto $S$. Current concepts on the transmission of bacteria and parasites by blood components. Sao Paulo Med J. 1995;113(6):1036-52. doi: 10.1590/S1516-31801995000600007. [PubMed: 8731290].

15. Siegel SE, Lunde MN, Gelderman AH, Halterman RH, Brown JA, Levine AS, et al. Transmission of toxoplasmosis by leukocyte transfusion. Blood. 1971;37(4):388-94. [PubMed: 4927414].

16. Karimi G, Mardani A, Zadsar M. Prevalence of Toxoplasma gondii among Iranian blood donors: A narrative review article. Iran Parasitol. 2016;11(1):10-8. [PubMed: 27095963]. [PubMed Central: PMC4835458].
17. Saki J, Foroutan M, Khodkar I, Khodadadi A, Nazari L. Seroprevalence and molecular detection of Toxoplasma gondii in healthy blood donors in southwest Iran. Transfus Apher Sci. 2019;58(1):79-82. doi: 10.1016/j.transci.2018.12.003. [PubMed: 30579749].

18. Zainodini N, Zare-Bidaki M, Abdollahi SH, Afrooz M, Ziaali N, Ebrahimian $\mathrm{M}$, et al. Molecular and serological detection of acute and latent toxoplasmosis using real-time PCR and ELISA techniques in blood donors of Rafsanjan city, Iran, 2013. Iran J Parasitol. 2014;9(3):336-41. [PubMed: 25678917]. [PubMed Central: PMC4316564].

19. Elsheikha HM, Azab MS, Abousamra NK, Rahbar MH, Elghannam DM, Raafat D. Seroprevalence of and risk factors for Toxoplasma gondii antibodies among asymptomatic blood donors in Egypt. Parasitol Res. 2009;104(6):1471-6. doi: 10.1007/s00436-009-1350-z. [PubMed: 19198880].

20. Gholami M, Maghsod AH, Mohammadi A, Fallah N, Fallah M. [Seroprevalence of Toxoplasmosis in blood donors of Hamadan transfusion Center in 2013]. Yafte. 2015;17(2). Persian.

21. Bahhaj R, Ahmadpour E, Mahami-Oskouei M, Fallah E, Shamsasenjan K, Safaiyan A. Toxoplasma gondii infection and related risk factors among blood donors in northwest Iran. Arch Clin Infect Dis. 2017;12(2) e62005. doi: 10.5812/archcid.62005.

22. Notomi T, Okayama H, Masubuchi H, Yonekawa T, Watanabe K, Amino $\mathrm{N}$, et al. Loop-mediated isothermal amplification of DNA. Nucleic Acids Res. 2000;28(12). E63. doi: 10.1093/nar/28.12.e63. [PubMed: 10871386]. [PubMed Central: PMC102748].

23. Lin Z, Zhang Y, Zhang H, Zhou Y, Cao J, Zhou J. Comparison of loop-mediated isothermal amplification (LAMP) and real-time PCR method targeting a 529-bp repeat element for diagnosis of toxoplasmosis. Vet Parasitol. 2012;185(2-4):296-300. doi: 10.1016/j.vetpar.2011.10.016. [PubMed: 22051073].

24. Fallahi S, Seyyed Tabaei SJ, Pournia Y, Zebardast N, Kazemi B. Comparison of loop-mediated isothermal amplification (LAMP) and nestedPCR assay targeting the RE and B1 gene for detection of Toxoplasma gondii in blood samples of children with leukaemia. Diagn Microbiol Infect Dis. 2014;79(3):347-54. doi: 10.1016/j.diagmicrobio.2014.02.014. [PubMed: 24792838].

25. Rezaei F, Sarvi S, Sharif M, Hejazi SH, Pagheh AS, Aghayan SA, et al. A systematic review of Toxoplasma gondii antigens to find the best vaccine candidates for immunization. Microb Pathog. 2019;126:172-84 doi:10.1016/j.micpath.2018.11.003. [PubMed: 30399440].

26. Ferdowsi S, Farsi L, Tajalli S, Soltani H. Seroprevalence anti-Toxoplasma gondii antibodies and anti-epstein-barr virus (ebv) antibody among volunteer blood donors referred Gonabad Blood Transfusion Organization. JZabol Univ Med Sci Health Serv. 2013;5(2):60-9.

27. Jafari Modrek M, Mousavi M, Saravani R. Toxoplasma gondii Seroprevalence among blood donors in Zahedan, Southeastern Iran. Int Infect. 2014;1(2). doi: 10.17795/iji-21111.

28. Zarean M, Shafiei R, Gholami M, Fata A, Rahmati Balaghaleh M, Kariminik A, et al. seroprevalence of anti-Toxoplasma gondii antibodies in healthy voluntary blood donors from Mashhad City, Iran. Arch Iran Med. 2017;20(7):441-5. [PubMed: 28745905].

29. Tappeh KH, Musavi J, Safa MB, Galavani H, Alizadeh H. Prevalence of IgG and IgM anti-Toxoplasma gondii Antibodies in blood donors at Urmia Blood Transfusion Organization, Iran. Turkiye Parazitol Derg. 2017;41(1):1-4. doi: 10.5152/tpd.2017.5066. [PubMed: 28483726]

30. Mahmoudvand H, Saedi Dezaki E, Soleimani S, Baneshi MR, Kheiran dish F, Ezatpour B, et al. Seroprevalence and risk factors of Toxoplasma gondii infection among healthy blood donors in south-east of Iran Parasite Immunol. 2015;37(7):362-7. doi: 10.1111/pim.12198. [PubMed: 25891186].

31. Coelho RA, Kobayashi M, Carvalho LB Jr. Prevalence of IgG antibodies specific to Toxoplasma gondii among blood donors in Recife, Northeast Brazil. Rev Inst Med Trop Sao Paulo. 2003;45(4):229-31. doi: 10.1590/S0036-46652003000400011. [PubMed:14502353].

32. Walle F, Kebede N, Tsegaye A, Kassa T. Seroprevalence and risk factors for Toxoplasmosis in HIV infected and non-infected individ- 
uals in Bahir Dar, Northwest Ethiopia. Parasit Vectors. 2013;6(1):15 doi: 10.1186/1756-3305-6-15. [PubMed: 23324409]. [PubMed Central: PMC3556116].

33. van der Colf BE, Noden BH, Wilkinson R, Chipare I. Low seroprevalence of antibodies to Toxoplasma gondii in blood donors in central Namibia. Southern Afr J Infect Dis. 2015;29(3):101-4. doi 10.1080/23120053.2014.11441579.

34. Sundar P, Mahadevan A, Jayshree RS, Subbakrishna DK, Shankar SK. Toxoplasma seroprevalence in healthy voluntary blood donors from urban Karnataka. Indian J Med Res. 2007;126(1):50-5. [PubMed: 17890824].

35. Ormazdi H, Razmju E, Memar A, Akhlaghi L, Hadighi R, Sanikhani N. Investigation of antibodies (IgG and IgM) against Toxoplasma gondi in blood donors referred to Tehran Blood Transfusion Organization by ELISA.J Urmia Univ Med Sci. 2010;21(2):212-6.

36. Mansouri A, Adhami Mojarad MR, Badfar G, Abasian L, Rahmati S, Kooti W, et al. Epidemiology of Toxoplasma gondii among blood donors in Iran: A systematic review and meta-analysis. Transfus ApherSci.2017;56(3):404-9. doi:10.1016/j.transci.2017.03.011. [PubMed 28433405].

37. Shaapan RM, Abd El Wah WM, Abd El Haf MED, Elfadaly HA, Ahmed Hamd D. Toxoplasma gondii infection and associated sociodemographic and behavioral risk factors among blood donors. Asian J Epidemiol. 2018;11(2):52-8. doi: 10.3923/aje.2018.52.58.

38. Shaddel M, Mirzaii-Dizgah I, Hoshangi M. Anti-Toxoplasma gondii antibody levels in blood supply of Shiraz Blood Transfusion Institute, Iran. Iran J Parasitol. 2014;9(1):120-4. [PubMed: 25642268]. [PubMed
Central: PMC4289869].

39. Zhang H, Thekisoe OM, Aboge GO, Kyan H, Yamagishi J, Inoue N, et al. Toxoplasma gondii: Sensitive and rapid detection of infection by loop-mediated isothermal amplification (LAMP) method. Exp Parasitol. 2009;122(1):47-50. doi: 10.1016/j.exppara.2009.01.012. [PubMed: 19545521].

40. Liesenfeld O, Press C, Montoya JG, Gill R, Isaac-Renton JL, Hedman K, et al. False-positive results in immunoglobulin $\mathrm{M}$ (IgM) toxoplasma antibody tests and importance of confirmatory testing: The Platelia Toxo IgM test. J Clin Microbiol. 1997;35(1):174-8. [PubMed: 8968902]. [PubMed Central: PMC229533].

41. Sadooghian S, Mahmoudvand H, Mohammadi MA, Nazari Sarcheshmeh N, Tavakoli Kareshk A, Kamiabi H, et al. Prevalence of Toxoplasma gondii infection among healthy blood donors in northeast of Iran. Iran J Parasitol. 2017;12(4):554-62. [PubMed: 29317880]. [PubMed Central: PMC5756305].

42. Moshfe A, Arefkhah N, Sarkari B, Kazemi S, Mardani A. Toxoplasma gondii in blood donors: A study in boyer-ahmad county, southwest Iran. Interdiscip Perspect Infect Dis. 2018;2018:3813612. doi: 10.1155/2018/3813612. [PubMed: 29849610]. [PubMed Central: PMC5925030].

43. Sun XM, Ji YS, Liu XY, Xiang M, He G, Xie L, et al. Improvement and evaluation of loop-mediated isothermal amplification for rapid detection of Toxoplasma gondii infection in human blood samples. PLoS One. 2017;12(1). e0169125. doi: 10.1371/journal.pone.0169125. [PubMed: 28056092]. [PubMed Central: PMC5215908]. 